\title{
Dexamethasone prevents relapse after emergency department treatment of acute migraine: a randomized clinical trial
}

\author{
Grant D. Innes, MD;* Iain Macphail, MD; $†$ Edward C. Dillon, BSc, PharmD; \\ Cathy Metcalfe, RN, BHS; $\dagger$ Min Gao, PhD
}

\begin{abstract}
:
Objective: To determine whether the addition of intravenous dexamethasone to standard emergency department (ED) migraine therapy would decrease the incidence of severe recurrent headache 24 to 48 hours after initial treatment.

Methods: Patients aged 19 to 65 years whose headache was severe enough to require parenteral therapy and who met International Headache Society migraine criteria were eligible for this randomized, double-blind trial. The study was conducted in the ED of 2 community hospitals, 1 of which was a tertiary referral centre. Exclusion criteria included pregnancy, focal findings, fever, meningismus, allergy to the study drug, active peptic ulcer disease and diabetes mellitus. Demographic and clinical data, including headache severity, were recorded. After abortive therapy (antiemetics, intravenous nonsteroidal agents, dihydroergotamine or opioids), blinded nurses administered dexamethasone (24 mg intravenously) or placebo. Patients recorded headache severity on a Visual Analogue Scale (VAS) at time T=0, T= $30 \mathrm{~min}$ utes and $T=60$ minutes and at discharge. They were contacted 48 to 72 hours later and asked whether they had suffered a recurrence of their headache, categorized as class A (severe, provoking another physician visit), class B (severe, interfering with daily activity but not provoking a physician visit), class C (mild, requiring self-medication but not limiting activity) or class $\mathrm{D}$ (mild, requiring no treatment).

Results: Two of 100 patients were lost to follow-up, leaving 98 in the study sample. Placebo recipients were more likely to be female; other baseline characteristics were similar between groups. Median VAS pain score was $83 \mathrm{~mm}$ on ED arrival, $35 \mathrm{~mm}$ after initial treatment and $12 \mathrm{~mm}$ on discharge. At followup, 65 of 98 patients had suffered headache recurrence. In the placebo versus dexamethasone groups, respectively, the results were 11 versus 0 in class $A, 11$ versus 9 in class $B, 7$ versus 11 in class $C$ and 4 versus 12 in class $D$. Regarding the primary outcome, 9 of 49 dexamethasone patients (18\%) and 22 of 49 placebo patients (45\%) had severe (classes A and B) recurrent headache (odds ratio $0.28 ; 95 \%$ $\mathrm{Cl}, 0.11$ to $0.69 ; p=0.005)$.

Conclusions: Migraine recurrence is common after "successful" ED treatment. Inflammation may be a critical factor in migraine genesis. Intravenous dexamethasone decreases the incidence of severe recurrent headache after ED treatment and should be offered to patients thought to be at risk of recurrent headache.
\end{abstract}

RÉSUMÉ ANALYTIQUE :

Objectif : Déterminer si l'addition de dexaméthasone au traitement standard de la migraine à l'urgence permettrait de réduire la fréquence de céphalées sévères et récurrentes de 24 à 48 heures après le traitement initial.

From the *Department of Emergency Medicine, St. Paul's Hospital, and The Centre for Health Evaluation and Outcome Sciences, Vancouver, BC; the †Department of Emergency Medicine and $\ddagger$ Department of Pharmacy, Royal Columbian Hospital, New Westminster, BC; and §The Centre for Health Evaluation and Outcome Sciences, St. Paul's Hospital, Vancouver, BC

This article has been peer reviewed. 
Méthodes : Des patients âgés entre 19 et 65 ans dont les maux de tête étaient suffisamment violents pour nécessiter une thérapie parentérale et qui répondaient aux critères de la Société Internationale des céphalées étaient éligibles à participer à cet essai randomisé en double insu. L'étude fut menée à l'urgence de deux hôpitaux communautaires, dont l'un était un centre de consultation de soins tertiaires. Les critères d'exclusion comprenaient la grossesse, les signes en foyer, la fièvre, le méningisme, l'allergie au médicament à l'étude, un ulcère gastro-duodénal en évolution et le diabète sucré. Les données démographiques et cliniques, dont la sévérité du mal de tête, furent enregistrées. Les autres traitements ayant échoué (antiémétiques, agents non stéroidiens par i.v., dihydroergotamine ou opiacés), des infirmières à l'insu administrèrent de la dexaméthasone (24 mg i.v.) ou un placébo. Les patients enregistrèrent la sévérité du mal de tête sur une échelle visuelle analogique (EVA) au temps $T=0, T=30$ minutes, et $T=60$ minutes et au moment du congé de l'hôpital. On communiqua avec eux de 48 à 72 heures plus tard et on leur demanda si leur mal de tête était réapparu. Les réponses furent classées par catégories, la classe $A$ (mal de tête sévère suscitant une nouvelle visite chez le médecin), la classe $B$ (mal de tête sévère perturbant les activités quotidienne mais sans visite chez le médecin), la classe C (léger mal de tête nécessitant l'auto-médication mais ne limitant pas l'activité) ou la classe D (léger mal de tête ne nécessitant aucun traitement).

Résultats : Deux des 100 patients ne répondirent pas au suivi, l'échantillon à l'étude ne comportant plus que 98 sujets. Un plus grand nombre de femmes avaient reçu le placébo; les autres caractéristiques initiales de base étaient semblables pour les deux groupes. La cote de douleur moyenne à l'EVA était de $83 \mathrm{~mm}$ à l'arrivée à l'urgence, de $35 \mathrm{~mm}$ après le traitement initial et de $12 \mathrm{~mm}$ au moment du congé. Lors du suivi, 65 des 98 patients avaient eu une récurrence. Les résultats respectifs pour le groupe placébo et le groupe dexaméthasone étaient les suivants : 11 versus 0 pour la classe A, 11 versus 9 pour la classe B, 7 versus 11 pour la classe $C$ et 4 versus 12 pour la classe D. Pour ce qui est de l'issue immédiate, 9 des 49 patients traités à la dexaméthasone (18\%) et 22 des 49 patients du groupe placébo (45\%) présentèrent un mal de tête sévère (classes $A$ et $B$ ) et récurrent (rapport de probabilité 0,$28 ;$ IC $95 \%, 0,11$ à 0,$69 ; p=0,005$ ).

Conclusions : La récurrence de migraines est courante après un traitement «réussi» à l'urgence. L'inflammation peut constituer un facteur critique dans la genèse de la migraine. La dexaméthasone intraveineuse diminue la fréquence des maux de tête sévères récurrents après le traitement à l'urgence et devrait être offerte aux patients chez qui une telle récurrence est probable.

Key words: migraine, headache, analgesia, emergency department, corticosteroids, dexamethasone

\section{Introduction}

Migraine is a common and important problem in the emergency department (ED). Numerous agents, including nonsteroidal anti-inflammatory drugs (NSAIDs), ${ }^{1,2}$ antiemetics, $^{3-6}$ phenothiazines $^{3,7-13}$ and serotonin agonists ${ }^{1,3,8,9,14-20}$ alleviate acute migraines. Valid comparative trials are scarce, but available data suggest that in the absence of drugdependence the likelihood of success with any of these agents is $60 \%$ to $70 \%{ }^{21}$ Although the acute headache can generally be relieved, $8 \%$ to $66 \%$ of patients will suffer a recurrence within 48 hours. ${ }^{8,11,15,19,22-26}$

Many physicians believe that extracranial vasodilatation is integral to migraine genesis, yet it is clear that these headaches are not simply vascular phenomena, and existing data support the hypothesis that inflammation is a critical mechanism..$^{19,27-30}$ If so, then modulation of the inflammatory process may be an important component of therapy. This suggests a possible role for corticosteroids in the treatment of acute migraine, status

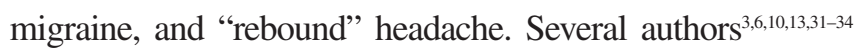
have advocated corticosteroids for migraine, but there is little evidence to support this practice. If corticosteroids enhance the success of abortive therapy or decrease the incidence of recurrent headache, this would represent an important advance in migraine treatment. To date, these questions have not been addressed in a randomized clinical trial.

Our objective was to determine whether the addition of intravenous (IV) dexamethasone to standard ED migraine therapy would decrease the incidence of severe recurrent headache 24 to 48 hours after initial treatment. The null hypothesis was that there is no difference in the rate of severe recurrent headache in patients treated with IV dexamethasone plus standard therapy versus those receiving standard therapy alone. The alternative hypothesis was that dexamethasone (24 mg intravenously, administered as a single-dose in the ED) will lead to a $25 \%$ relative reduction in the rate of severe recurrent headache - assessed 48 to 72 hours post-treatment. 


\section{Methods}

\section{Design}

This was a double-blind, placebo-controlled, randomized effectiveness trial.

\section{Setting}

Study participants presented to 1 of 2 urban, community hospital EDs. The Royal Columbian Hospital is a tertiary care facility with an annual ED census of 65000 visits. Eagle Ridge Hospital has 35000 visits annually. Both are staffed by the same group of full-time emergency physicians.

\section{Subjects}

We enrolled a convenience sample of patients presenting to the ED with a chief complaint of headache. Patients were eligible if they were over 19 years of age, had a history of recurrent headaches and were suffering from an acute headache that the attending emergency physician considered was severe enough to require parenteral therapy. To fulfil International Headache Society (IHS) criteria for migraine without aura (Fig. 1), at least 3 of the following also had to be present: unilateral location; throbbing or pulsating quality; moderate or severe intensity (inhibits daily activity); aggravated by routine physical activity; nausea or vomiting; photophobia or phonophobia. Patients were excluded if they had any of the following criteria: pregnancy or possible pregnancy; focal neurologic findings; fever or meningismus; allergy to study drug; active peptic ulcer disease; insulindependent diabetes; already on systemic corticosteroids for another condition, or already treated in this study. The study was approved by the institutions' clinical investigation committee and all subjects provided written informed consent.

Fig. 1. International Headache Society diagnostic criteria for migraine without aura ${ }^{20}$

A. At least 5 attacks fulfilling criteria $B-D$

B. Headache lasts 4 to 72 hours

C. Headache has 2 or more of the following: - unilateral

- pulsating

- moderate or severe (inhibits daily activities)

- aggravated by physical activity

D. Headache is associated with one of:

- nausea or vomiting

- photophobia/phonophobia

E. Other organic cause (i.e., infection, bleed, tumour) not known or suspected.

\section{Intervention}

All consenting, eligible patients underwent clinical and neurologic examinations. Critical physical findings, including neck stiffness, mentation, presence or absence of focal neurologic findings and apparent (subjective) patient distress, based on a 3-point categorical scale (mild, moderate or severe) were recorded by the treating physician. Baseline demographic data, vital signs, and characteristics and duration of the headache were recorded on a standard data form.

At time $\mathrm{T}=0$, prior to any treatment, patients rated their headache severity by marking a $10-\mathrm{cm}$ Visual Analogue Scale (VAS). They then received abortive migraine therapy based on the attending emergency physician's preference. Further abortive agents, including dopamine antagonists, opioids, intravenous NSAIDs, and dihydroergotamine, were given as necessary to control headache (Table 1). After abortive therapy was under way, patients received dexamethasone $24 \mathrm{mg} \mathrm{IV}$, or placebo, based on a predetermined randomization schedule. Active drug and placebo were pre-

\begin{tabular}{|c|c|c|}
\hline Characteristic & $\begin{array}{l}\text { Placebo } \\
(n=49)\end{array}$ & $\begin{array}{l}\text { Dexamethasone } \\
\qquad(n=49)\end{array}$ \\
\hline Age, mean (SD) & $36(8.6)$ & $34(9.9)$ \\
\hline Female gender, no. (\%) & $42(85)$ & $36(74)$ \\
\hline \multicolumn{3}{|l|}{$\begin{array}{l}\text { Median HA severity, VAS pain } \\
\text { score in } \mathrm{mm} \text { (interquartile range) }\end{array}$} \\
\hline Initial & $84(76-93)$ & $83(75-94)$ \\
\hline At discharge & $11(3-20)$ & $15(5-22)$ \\
\hline $\begin{array}{l}\text { HA rated "severe" by research } \\
\text { staff, no. (\%) }\end{array}$ & $11(22)$ & $13(27)$ \\
\hline $\begin{array}{l}\text { Median HA duration, } \mathrm{h} \\
\text { (interquartile range) }\end{array}$ & $11(6-30)$ & $12(5-28)$ \\
\hline $\begin{array}{l}\text { Patients requiring }>1 \text { abortive } \\
\text { agent, no. }(\%)\end{array}$ & $23(47)$ & $24(49)$ \\
\hline \multicolumn{3}{|l|}{$\begin{array}{l}\text { During ED treatment, no. (\%) } \\
\text { patients receiving }\end{array}$} \\
\hline Intravenous antiemetic & $47(96)$ & $47(96)$ \\
\hline metoclopramide & 36 & 43 \\
\hline prochlorperazine & 7 & 3 \\
\hline chlorpromazine & 3 & 1 \\
\hline dimenhydrinate & 1 & 0 \\
\hline Intravenous ketorolac & $14(29)$ & $14(29)$ \\
\hline Parenteral opioid & $7(14)$ & $3(6)$ \\
\hline meperidine & 5 & 2 \\
\hline morphine & 2 & 1 \\
\hline Intravenous dihydroergotamine & $4(8)$ & $1(2)$ \\
\hline
\end{tabular}


prepared in identical numbered syringes and administered by blinded ED nursing staff over 15 minutes from unlabelled mini-bags.

Patients rated their VAS headache severity 30 minutes after each abortive medication and at the time of discharge, when they were asked to report any adverse effects. The ED phase of the trial ended when patients indicated that their headache was relieved and they felt comfortable enough to go home.

\section{Outcomes}

Patients were contacted by telephone 48 to 72 hours later. From a standardized questionnaire, study nurses asked them whether they had suffered a recurrent headache after ED discharge. Recurrent headaches were categorized as class A (severe, provoking another physician visit), class B (severe, interfering with daily activity but not provoking another physician visit), class $\mathrm{C}$ (mild, requiring self-medication but not limiting daily activity) or class $\mathrm{D}$ (mild, requiring no treatment). Patients were also asked whether they had suffered any adverse effects and, specifically, whether they had experienced drowsiness or motor restlessness. At follow-up we did not differentiate between recurrent and persistent headaches. Some patients had headaches that worsened after incomplete relief in the ED (persistent). Others had headaches that resolved, then recurred during the follow-up period (recurrent). Both are referred to in this paper as "recurrent." Our primary outcome was the proportion of patients in each group who experienced a severe recurrent headache that provoked another physician visit or precluded normal activity (class A or B).

\section{Sample size}

To calculate sample size, we estimated that $70 \%$ of control patients would not have a severe recurrent headache at follow-up and that a $25 \%$ relative improvement would be clinically important. Assuming patients to be unpaired, using a 2 -sided test for significance, and setting alpha at 0.05 and beta at 0.20 , we calculated that 87 patients were necessary in each group.

\section{Data analysis}

To determine the statistical significance of observed differences in categorical outcome variables, $\chi^{2}$ analysis was used. Where appropriate, Yates' correction was applied. Intervals of $95 \%$ confidence were calculated around critical proportions. Logistic regression analysis was used to evaluate the strength of the treatment effect after controlling for possible confounding variables, including age, sex, headache duration, and headache severity at presentation and on discharge. Headache duration, as a confounding variable, was analysed as interval data per hour of headache duration. A subgroup analysis (patients with more than 12 hours' pain versus those with less than 12 hours' pain) was performed to determine whether there was significant interaction between treatment effect and headache duration. A single interim analysis was planned for $n=100$ patients. The study was to be stopped if either group showed a significant $(p<0.05)$ reduction in severe recurrent headache and if the 2 groups were otherwise similar.

\section{Results}

The interim analysis showed a clinically and statistically significant outcome difference between groups, so the study was terminated early. At termination, 118 patients met the inclusion criteria, having acute severe headaches that fulfilled IHS criteria for migraine without aura. Four were excluded because of fever, 2 because of pregnancy, and 1 each because of diabetes, steroid allergy and active peptic ulcer disease. One patient was excluded because she was already receiving systemic steroids for an unrelated condition. Six eligible patients refused to enter the study, 1 agreed to the trial but left the ED before the study drug was given, and in 1 case the drug was withheld for reasons that were not clear. One hundred patients received the study drug and 2 were lost to follow-up, leaving 98 in the primary analysis.

Median VAS pain scores were $83 \mathrm{~mm}$ at presentation, 35 $\mathrm{mm}$ after initial abortive drug treatment and $12 \mathrm{~mm}$ at discharge. Fifty-one (52\%) patients required only 1 abortive intravenous drug treatment; $34(35 \%)$ required 2, and 13 (13\%) required 3. Table 1 shows that prognostic baseline parameters were similar between groups, suggesting adequate randomization.

In the dexamethasone versus placebo groups, respectively, the initial abortive therapy was IV metoclopramide in 41 versus 36 cases, IV prochlorperazine in 3 versus 6 cases, IV ketorolac in 3 cases versus 1 case, IV chlorpromazine in 1 case versus 3 cases, IM meperidine in 1 case versus 2 cases, and IV dimenhydrinate in 0 versus 1 case. When a second abortive treatment was required $(n=47)$, physicians chose IV ketorolac in 13 versus 12 cases, IV metoclopramide in 7 versus 3 cases, IV dihydroergotamine in 1 case versus 4 cases, IM meperidine in 1 case versus 3 cases, IV morphine in 1 versus 1 case, and IV chlorpromazine in 1 versus 0 case.

At 48-hour follow-up, 33 patients (33.7\%) were pain free and $65(66.3 \%)$ had a recurrent or persistent headache. Table 2 shows the distribution of recurrent headaches. With respect to the primary outcome, 9 of 49 dexamethasone 
patients $(18.4 \% ; 95 \% \mathrm{CI}, 7.6 \%$ to $29.2 \%)$ and 22 of 49 placebo patients $(44.9 \%$; $95 \%$ CI, $31.0 \%$ to $58.8 \%$ had severe recurrent headache (odds ratio $0.28 ; 95 \% \mathrm{CI}, 0.11$ to $0.69 ; p=0.005)$. This treatment effect remained significant after controlling for possible confounding variables including gender, and headache severity, duration and response to abortive therapy (odds ratio $0.32 ; 95 \% \mathrm{CI}, 0.11$ to $0.83 ; p=$ 0.02). There was an association between increasing headache duration before treatment and severe headache recurrence after treatment (odds ratio per hour 1.01; 95\% CI, 1.00 to $1.02 ; p=0.06$ ). The other independent variables noted above did not show a significant relationship. Subgroup analysis comparing patients with more than 12 hours of pain to those with less than 12 hours of pain showed that the treatment effect was similar regardless of headache duration ( $p$ for interaction $=0.23$ ).

Table 3 shows that minor adverse effects were common. These were self-limited and generally attributed to the abortive therapy rather than to the experimental agent. Overall, dexamethasone patients reported fewer adverse effects than placebo-treated patients. One major adverse event occurred: a spontaneous abortion 3 weeks after the study drug was given in a metoclopramide/placebo-treated patient who had assured study staff that she was not pregnant at the time of enrolment.

\section{Discussion}

Emergency physicians tend to define headache treatment as successful if the patient leaves the ED feeling better than he or she did on arrival; however, several studies ${ }^{8,11,15,19,22-26}$ have shown that migraine victims often suffer recurrent headaches after discharge. Reported recurrence rates are $8.1 \%$ for methotrimeprazine, ${ }^{11} 34 \%$ to $53 \%$ for sumatrip$\tan ,{ }^{19,22-24} 11 \%$ to $66 \%$ for chlorpromazine, ${ }^{8,25} 13 \%$ to $47 \%$ for dihydroergotamine, ${ }^{8,15} 24 \%$ to $56 \%$ for meperidine ${ }^{11,26}$ and $87 \%$ for intramuscular ketorolac. ${ }^{26}$ This suggests that as emergency physicians we need to re-evaluate our management of acute headaches and our definition of therapeutic success.

In this study, two-thirds of our patients suffered a recurrent headache and one-third suffered a severe recurrent headache after "successful" abortive therapy. The study confirms our hypothesis: that IV dexamethasone decreases the rate of severe recurrent headache after ED treatment. Our most dramatic finding was that $22 \%$ of placebo-treated patients and $0 \%$ of dexamethasone-treated patients had a recurrent headache severe enough to cause them to seek additional medical care in the days after their ED visit.
These data support the underlying premise that inflammatory mediators play an important role in migraine pathophysiology. It is the authors' belief, supported by the results of this trial, that failure to address the inflammatory component of headache leads to higher recurrence rates.

Many physicians view migraine as a vascular event, where transient vasoconstriction causes an aura, then vasodilatation causes a headache. Physicians working from this simplistic model are likely to believe that when the symptoms are alleviated the problem has been solved. It is important to recognize, however, that other factors are operational.

In migraine victims, poorly defined noxious triggers activate trigeminal sensory afferent nerves. Trigeminal nociceptors release vasoactive neuropeptides that mediate platelet aggregation, mast cell degranulation, vasodilatation, and increase vascular permeability. ${ }^{27,28}$ Antidromic trigeminal activation provokes neurogenic inflammation at extracranial arteries and in pain-sensitive dural regions. Ongoing vasodilatation, neurogenic plasma extravasation, sensitization, hyperalgesia and nociceptor recruitment are attributable to numerous inflammatory mediators including 5-hydroxytryptamine, substance $P$, bradykinin, histamine, prostaglandins, leukotrienes, and CGRP (calcitonin gene-

\begin{tabular}{|c|c|c|}
\hline Severity (class) & $\begin{array}{l}\text { Placebo } \\
(n=49)\end{array}$ & $\begin{array}{l}\text { Dexamethasone } \\
\qquad(n=49)\end{array}$ \\
\hline A - Severe; provoked repeat MD visit & 11 & 0 \\
\hline B - Severe; precluded normal activity & 11 & 9 \\
\hline$A+B$ - Severe recurrent headache* & $22(45)$ & $9(18)$ \\
\hline $\begin{array}{c}\text { C - Mild; analgesic necessary; } \\
\text { no activity limitation }\end{array}$ & 7 & 11 \\
\hline D - Mild; no treatment necessary & 4 & 12 \\
\hline
\end{tabular}

\begin{tabular}{lcc}
\multicolumn{3}{l}{ Table 3. Number (and \%) of adverse events } \\
$\begin{array}{lcc}\text { Placebo } \\
\left(n=47^{*}\right)\end{array}$ & $\begin{array}{c}\text { Dexamethasone } \\
\left(n=37^{*}\right)\end{array}$ \\
\hline Restlessness & $9(19)$ & $15(31)$ \\
Drowsiness & $21(43)$ & $12(24)$ \\
Nausea & $15(31)$ & $6(12)$ \\
$\begin{array}{l}\text { Dizziness } \\
\text { Tingling, numbness, or }\end{array}$ & 0 & $2(4)$ \\
swelling sensations & 0 & $2(4)$ \\
"Moodiness" & $1(2)$ & 0 \\
$\begin{array}{l}\text { Spontaneous abortion } \\
\text { (3 wk post-treatment) }\end{array}$ & $1(2)$ & 0
\end{tabular}


related peptide). Moskovitz ${ }^{27}$ postulated that trigeminalvascular activation is the final common pathway in migraine. Lance ${ }^{29}$ suggests that migraine is a hereditary sensitivity of neurovascular reflexes, that migraine sufferers are prone to trigeminal-vascular "disinhibition," and that various trigger factors activate the trigeminal-vascular system, causing antidromic release of vasoactive mediators.

5-hydroxytryptamine receptor agonists, including dihydroergotamine and sumatriptan, block mediator release at pain-sensitive vascular and meningeal structures, thus inhibiting neurogenic plasma extravasation and inflammation. ${ }^{19,27,28,30}$ The effectiveness of these agents in migraine supports the contention that neurogenic inflammation is an important pathophysiologic mechanism in headache generation and recurrence; however, the effectiveness of other agents, particularly dopamine antagonists and antiemetics, suggests that multiple receptors are involved. We chose, therefore, to study corticosteroids, which have "broad spectrum" anti-inflammatory and membrane-stabilizing effects.

Previous evidence for steroids in migraine is weak. In an uncontrolled study, Saadah ${ }^{10}$ reported $80 \%$ to $90 \%$ response rates to dexamethasone (10 to $20 \mathrm{mg}$ intravenously). In another uncontrolled study, ${ }^{3}$ Stiller reported good pain relief and no headache recurrence in 27 patients who received 100 $\mathrm{mg}$ of IV hydrocortisone in addition to antiemetics and dihydroergotamine. In a nonrandomized study of migraine headaches lasting more than 36 hours, Gallagher ${ }^{13}$ found that $8 \mathrm{mg}$ of IM dexamethasone in addition to meperidineprochlorperazine, reduced the incidence of recurrent headache from $71 \%$ to $28 \%$. While long-term corticosteroid therapy is associated with multiple adverse effects, singledose therapy is not. A MEDLINE search uncovered only 1 case report ${ }^{35}$ of an adverse effect (urticaria) attributed to single-dose dexamethasone.

Our 24-mg dexamethasone dose is atypical and warrants explanation. At study conception, we felt it was logical to use a long-acting agent, but the ideal drug and dose were unclear. We selected methylprednisolone as our first choice and agreed on $125 \mathrm{mg}$ intravenously, a dose commonly used in acute asthma. We subsequently switched to dexamethasone because of its greater stability at room temperature, which made it feasible to pre-prepare drug kits. The bioequivalent dose of dexamethasone is $24 \mathrm{mg}$.

Whereas previous studies reported headache recurrence rates after abortive therapy, our goal was to document both recurrence rate and level of disability associated with these headaches. We feared, however, that actively inquiring about recurrent headaches might lead to over-reporting (Hawthorne effect). To address this issue, we divided recur- rent headaches into the 4 categories defined. We thought that, although active follow-up might artificially increase the reporting of mild headaches, it was unlikely to "create" severe headaches. We defined our primary outcome as "severe" recurrent headaches that preclude normal activities or lead to additional physician visits, because these headaches are less sensitive to the Hawthorne effect and because they have the greatest impact on productivity and quality of life, thus are worth trying to prevent.

This study demonstrates that intravenously administered dexamethasone decreases the rate of severe recurrent headache after ED treatment, but an important question remains. Are there subgroups of migraine patients who are more likely to suffer recurrent headache, thus more likely to benefit from steroid treatment? Post-hoc regression analysis showed an association between increased headache duration and severe recurrent headache (odds ratio per hour $1.01 ; 95 \% \mathrm{CI}, 1.00$ to $1.02 ; p=0.06$ ), suggesting that the relative risk of recurrent severe headache increases by about $1 \%$ per hour of headache duration. However, subgroup analysis showed a nonsignificant interaction $(p=0.23)$ between headache duration and treatment effect, suggesting that dexamethasone's therapeutic benefit is not related to headache duration, and that the decision to administer dexamethasone should not be based on headache duration. Moreover, no other factors, including gender, headache severity at presentation or discharge, or number of abortive treatments required, were independent predictors of headache recurrence at 48 hours.

\section{Limitations and future questions}

Like many ED trials, we enrolled a convenience sample; therefore it is possible we have an unrecognized selection bias. In addition, our failure to standardize abortive therapy could conceivably introduce a bias if one group received different treatment from the other. We chose not to standardize abortive treatment because, in the real world, different drug combinations are often required and because all patients do not respond to a standard regimen. Moreover, patients often know what agents work best for them, and physicians often have treatment preferences. We felt that mandating specific abortive therapies would make the study more complex and inhibit both physicians and patients from participating. We assumed that the randomization process would assure treatment balance between groups. Table 1 suggests that it did.

Almost all of our study patients received dopamine antagonists, which raises 2 problems. First, it is conceivable that 
patients who do not receive these agents may have different rates of headache recurrence. Second, it is possible that dexamethasone may be more or less effective for patients not treated with dopamine antagonists. Because the number of patients who received "other" abortive treatments is small, and because most patients received drug combinations, subgroup and logistic regression analyses are not helpful in determining whether either of these problems is likely to be real.

This study shows that dexamethasone decreases recurrent headache but does not tell us whether it is useful as an abortive agent. And although we collected data on several abortive agents, we cannot draw any conclusions about which is the most effective for relief of acute headache. Although we believe that neurogenic inflammation is common to most headaches, and that physicians' compulsion to distinguish migraines from non-migraines is counterproductive, our study did not address whether dexamethasone is effective in patients who do not meet IHS migraine criteria. It is interesting to speculate that other steroid preparations, particularly methylprednisolone, may be useful in acute migraine, but we did not study this. The fact that dexamethasone recipients suffered fewer severe recurrences and had fewer repeat physician visits suggests that there are qualityof-life and productivity benefits to this therapy, but we did not perform a formal economic analysis and did not demonstrate these benefits. All of these are areas for future study.

\section{Conclusions}

Migraine recurrence is common after "successful" ED treatment. Single-dose dexamethasone ( $24 \mathrm{mg}$ intravenously) reduces the incidence of severe recurrent headache and decreases the proportion of patients forced to seek additional medical care. IV dexamethasone should be offered to ED patients with severe migraine who are thought to be at risk of recurrent headache. It is likely that this simple, lowcost intervention will reduce unnecessary health care utilization after "successful" ED migraine therapy. One study does not, however, define a standard of care, and we encourage other investigators to attempt to validate our findings in diverse ED settings.

Acknowledgements: This study was funded by the Department of Emergency Medicine, Royal Columbian Hospital, and supported by a grant from the Canadian Association of Emergency Physicians (CAEP). CAEP would like to acknowledge the contributions of Hoffmann-LaRoche Pharmaceuticals to the CAEP Research Fund. Statistical analysis was carried out by Min Gao, $\mathrm{PhD}$, of the Centre for Health Evaluation and Outcome Sciences, Vancouver, BC. No funding was received from the manufacturer of the study drug.

\section{References}

1. Klapper JA, Stanton JS. Ketorolac (IM) versus dihydroergotamine and metoclopramide (IV) in the treatment of migraine headache. Headache 1991;31:523-4.

2. Duarte C, Dunaway F, Turner L. Ketorolac versus meperidine and hydroxyzine in the treatment of acute migraine headache: a randomized, double blind trial. Ann Emerg Med 1992;21:1116-21.

3. Stiller J. Management of acute intractable headaches using intravenous therapy in an office setting. Headache 1992;32:514-5.

4. Tek DS, McClellan DS, Olshaker JS. A prospective, doubleblind study of metoclopramide for the control of migraine in the emergency department. Ann Emerg Med 1990;19:1083-7.

5. Ellis GL, Delaney J, DeHart DA, Owens A. The efficacy of metoclopramide in the treatment of migraine headache. Ann Emerg Med 1993;22:191-5.

6. Klapper J, Stanton J. The emergency treatment of acute migraine headache: a comparison of intravenous dihydroergotamine, dexamethasone, and placebo. Cephalgia 1991;2(Suppl 2):159-60.

7. Lane PL, McLellan BA, Baggoley CJ. Comparative efficacy of chlorpromazine and meperidine with dimenhydrinate in migraine headache. Ann Emerg Med 1989;18:360-5.

8. Bell R, Montoya D, Shuaib A, Lee MA. A comparative trial of three agents in the treatment of acute migraine headache. Ann Emerg Med 1990;19:1079-82.

9. Callaham M, Raskin N. A controlled study of dihydroergotamine in the treatment of acute migraine headache. Headache 1986;26:168-71.

10. Saadah HA. Abortive migraine therapy in the office with dexamethasone and prochlorperazine. Headache 1994;34:366-70.

11. Stiell IG, Dufour DG, Moher D, Yen M, Beilby WJ, Smith NA. Methotrimeprazine versus meperidine and dimenhydrinate in the treatment of severe migraine: a randomized, controlled trial. Ann Emerg Med 1991;20:1201-5.

12. Jones EB, Gonzales ER, Boggs JG, Grillo JA. Safety and efficacy of rectal prochlorperazine for the treatment of migraine in the emergency department. Ann Emerg Med 1994;24:237-41.

13. Gallagher RM. Emergency treatment of migraine. Headache 1986;26:74-5.

14. Klapper JA, Stanton JS. Clinical experience with patient administered subcutaneous dihydroergotamine in refractory headaches. Headache 1992;32:21-3.

15. Saadah HA. Abortive headache therapy with intramuscular dihydroergotamine. Headache 1992;32:18-20.

16. Jauslin P, Goadsby PJ, Lance JW. The hospital management of severe migrainous headache. Headache 1991;31:658-60.

17. Robbins L, Remmes A. Outpatient repetitive intravenous DHE. Headache 1992;32:455-8.

18. The Multinational Oral Sumatriptan and Cafergot Comparative Study Group. A randomized, double-blind comparison of sumatriptan and cafergot in the acute treatment of migraine. Eur Neurol 1991;31:314-22. 
19. The Subcutaneous Sumatriptan International Study Group. Treatment of migraine attacks with sumatriptan. N Engl J Med 1991;325:316-21.

20. Silberstein SD, Lipton RB. Overview of diagnosis and treatment of migraine. Neurology 1994;44(Suppl 7):S6-16.

21. Raskin NH. Acute and prophylactic treatment of migraine. Neurology 1993;43(Suppl 3):S39-42.

22. Neighbor ML. Sumatriptan: a new treatment for migraine. West J Med 1993;159:597-8.

23. Bateman DN. Sumatriptan. Lancet 1993;341:221-3.

24. Dahlof C, Ekbom K, Persson L. Clinical experiences from Sweden on the use of subcutaneously administered sumatriptan in migraine and cluster headache. Arch Neurol 1994;51:1256-61.

25. Cameron JD, Lane PL, Speechley M. Intravenous chlorpromazine vs. intravenous metoclopramide in acute migraine headache. Acad Emerg Med 1995;2:597-602.

26. Larkin GL, Prescott JE. A randomized, double-blind, comparative study of the efficacy of ketorolac versus meperidine in the treatment of severe migraine. Ann Emerg Med 1992;21:919-24.

27. Moskovitz MA. Neurogenic inflammation in the pathophysiology and treatment of migraine. Neurology 1993;43(Suppl 3):S16-20.

28. Buzzi MG, Moskowitz MA. Evidence for 5-HT1B/1D receptors mediating the antimigraine effect of sumatriptan and dihydroergotamine. Cephalgia 1991;11:165-8.

29. Lance JW. Current concepts of migraine pathogenesis. Neurology 1993;43(Suppl 3):S11-5.

30. Goadsby PJ, Gundlach AL. Localization of 3H-dihydroergotamine-binding sites in the cat central nervous system: relevance to migraine. Ann Neurol 1991;29:91-4.

31. Rapoport AM, Silberstein SD. Emergency treatment of headache. Neurology 1992;42(Suppl 2):43-4.

32. Saper J. Daily chronic headache. Neurol Clin 1990;8:891-901.

33. Schulman EA, Silberstein SD. Symptomatic and prophylactic treatment of migraine and tension headache. Neurology 1992; 42(Suppl 2):16-21.

34. Lobo RL, Landy S. Recommendations for the emergency treatment of migraine headache. J Tenn Med Assoc 1994;Feb:53-4.

35. Chan AT, O'Brien ME. Hypersensitivity to dexamethasone. BMJ 1993;306:109.

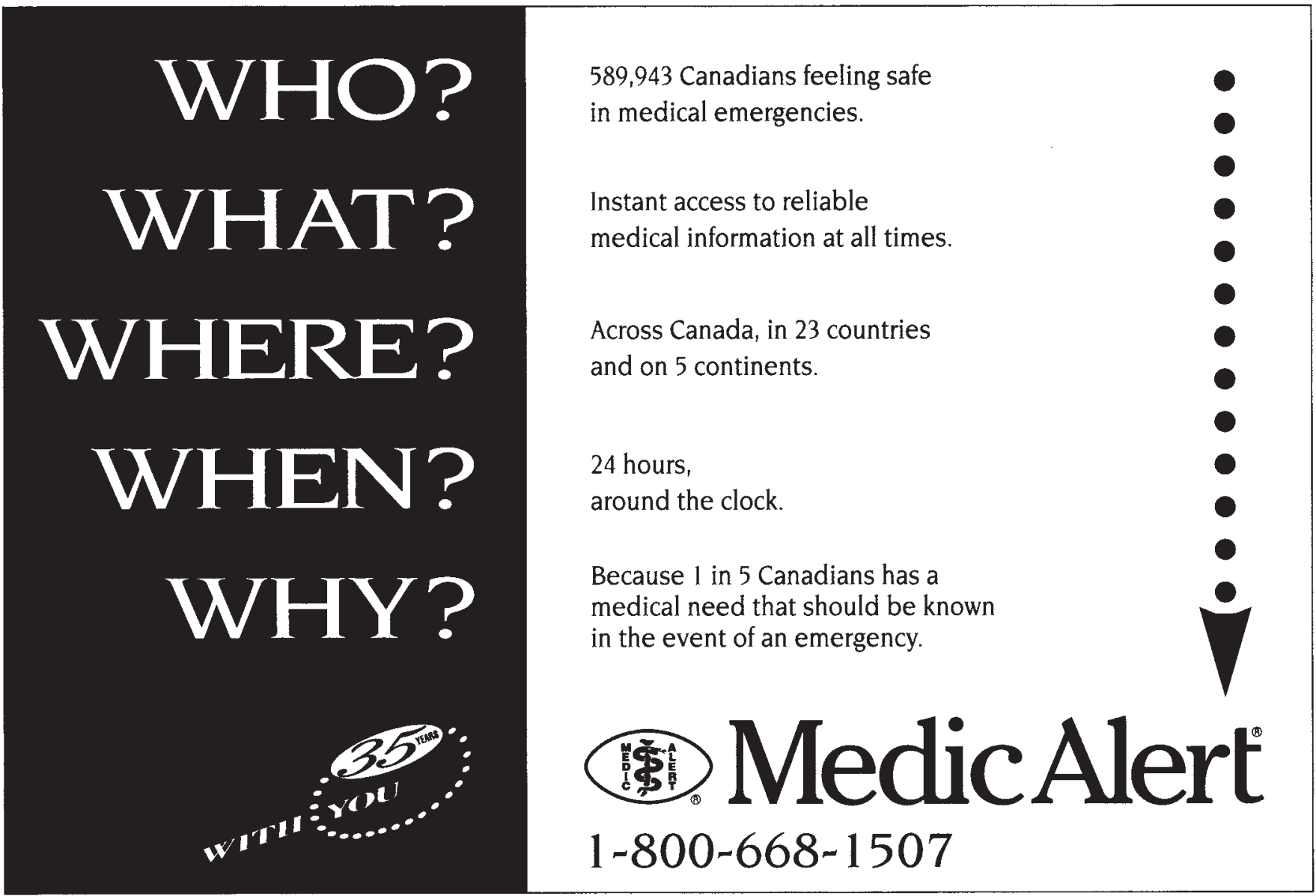

